\title{
1. The challenges we face
}

\section{OUR OBJECTIVE}

Pharmaceutical products play a central role in the prevention and treatment of disease. Making safe and effective pharmaceutical products available and affordable to individuals around the world is a central challenge to the global governance system. There are however myriad obstacles to achieving and maintaining effective worldwide availability of medicines.

Despite the fact that people around the world face largely similar challenges from disease, the policy framework for promoting innovation and regulating pharmaceutical supply is remarkably disjointed. Innovation policy, insofar as it is implemented at all, is established on a country-tocountry basis with minimal attention to coordination of research and development. Regulatory structures are almost equally fragmented. Each country has its own set of approval standards and regulatory procedures that must be dealt with, and only to a limited extent are there cooperative procedures or systems of mutual recognition. Corporate decisions concerning where to concentrate innovative efforts, what to produce, where to supply it and on what terms are based on the likely impact on profits and capital markets. ${ }^{1}$

There are wide disparities in levels of income both among countries and within countries. Prices that are reasonably affordable for individuals covered by health insurance in developed countries are likely to be unaffordable for individuals without health insurance in developed and developing countries. There are compelling needs for new medicines to treat diseases affecting both the rich and poor, such as diabetes, cancer, heart disease and the degenerative disorders of old age. Innovation in these areas is costly, yet even with substantial sums invested in research and development rates of innovation are surprisingly low. There are equally compelling needs for new medicines to treat disease conditions predominantly afflicting tropical regions where poverty rates are typically high. Far less is invested in the diseases of the poor because of a lack of market demand.

Medicines must be safe and effective. Making and keeping them so is a challenge for both private and public sector suppliers, for the regulators charged with promoting and protecting public health and for the policy makers who determine the framework within which regulation operates. 
This book examines the state of play of the international system for the development and supply of pharmaceutical products, and offers insights into how some of its challenges might be addressed. This system is enormously complex, with many moving parts, and there is not likely to be a quick fix for the many challenges. There are quite a few good ideas circulating among individuals and groups involved in formulating and implementing public policy in the field of medicines. This book was inspired by a roundtable among such individuals and groups hosted at Florida State University College of Law in the spring of 2007. At that roundtable, a number of the ideas discussed in this book were put forward and debated. The perspectives of some roundtable participants (and others) are incorporated at various points in the book, often in 'boxes'. Certainly new initiatives are needed in this field, and existing initiatives can and should be improved. We try to identify and explain those areas in which present policies are not working, and we offer suggestions regarding ways to improve them. We put forward our own proposals regarding directions that global public policy in the field of medicines should take. We do not claim a monopoly on promising ideas. We hope that this volume will succeed at least in moving the dialogue on these subjects forward.

\section{OVERVIEW}

Broadly speaking, there are two main categories of pharmaceutical products available on world markets. The first consists of newer originator medicines that are covered by patent protection (and/or the protection afforded in some instances by regulatory marketing exclusivity) and are typically sold at substantially higher prices than older established medicines. These originator medicines are developed, produced and sold by a handful of large multinational innovator companies, virtually all of which are based in the industrialized countries. The second category comprises generic medicines that are not (or are no longer) subject to patent or marketing exclusivity protection, and that are typically sold at substantially lower prices than originator products - commonly no more than 5 percent or 10 percent of the former price. Generic products are produced by a wide range of companies, ranging from small-scale to major multinational operators, based throughout the world. Generic pharmaceutical products sell in much larger volumes worldwide than originator products but, because of the immense price difference, gross revenues from sales of originator pharmaceuticals far exceed those from generic products. In 2007 total worldwide revenues from sales of pharmaceutical products amounted to approximately $\$ 650$ billion, of which $\$ 550$ billion went to the originator companies and $\$ 100$ billion to the generic companies. 


\section{INNOVATION POLICY}

Research and development (R\&D) aimed at the creation of new medicines is well understood to be necessary for the prevention and treatment of disease, and policies designed to promote innovation are a core component of global public policy in this field. Industry has done much through information campaigns to create the popular impression that major pharmaceutical companies have been consistently successful and efficient in ensuring innovation. In actual fact, as shown in Chapters 2 and 3 , the rate of innovation over the past decade has been decidedly low and the medicines developed have not always been well attuned to actual needs. Publicly funded research has made a significant contribution to the progress that has been made, a contribution that is not always sufficiently recognized.

The history of pharmaceutical innovation in modern times has involved periods of ebb and flow. A decade or two of rapid advance across a range of disease targets, generally based on a major technological advance, tends to be followed by a period in which few new treatments are developed, leading to concern as to whether the possibilities for innovation have been exhausted. Today we are in a period of low tide. Few significant new products are being introduced. Most of the products being brought to market by the pharmaceutical originators are minor modifications of earlier products. Perhaps most significantly, the widely proclaimed new era of biotechnology has yet to prove its ability to deliver on the enthusiastic claims that have been made for it.

A number of reasons have been suggested for the present low rate of innovation. First, the originator pharmaceuticals market is influenced by perverse incentives. Innovator companies find they are well rewarded for making minor modifications to previously patented products so as to effectively extend the life of monopolies (so-called 'evergreening'), a lowrisk practice that is highly lucrative. Perverse incentives also encourage investment in lifestyle drugs for which there is an ever-present consumer demand. Because capital markets are most concerned about profits, senior management at the originator companies is less inclined to take risks than to pursue relatively safe bets on product line extensions.

Second, it is sometimes suggested that the low-hanging fruit of pharmaceutical innovation already has been plucked. In particular, innovations for which synthetic organic chemistry is capable have largely been identified, and more complex large-molecule and biological materials innovations promised by the biotechnology industry are more costly and difficult than perhaps initially assumed.

It may be - as the industry suggests - that spectacular success in the biotechnology sector is just around the corner. Indeed, looked at from a 
long-term perspective, the biotech industry is in its infancy. The human organism may be more complicated than biotechnologists expected when they first began to decode the human genome, but patience may be rewarded as more complex biological systems are better understood.

Third, the originator pharmaceutical industry has gone through two decades of consolidation, and the net result of consolidation is a reduction in the targets of opportunity being pursued by R\&D laboratories.

Fourth, there is a disconnect - apparent worldwide - between research in university and research institute laboratories and the realities of producing new medicines. There is a shortage of individuals qualified and willing to 'translate' laboratory innovation into products entering the marketplace, and in a position where they can ensure that this happens.

A number of proposals have been made to retool the mechanisms for promoting innovation in the pharmaceutical sector. These include reforming patent laws so as to remove perverse incentives to extend the life of patents through minor modifications, changing the type of remedies that are available to patent holders able to prove infringement, developing alternative quasi-patents that would provide more limited types of exclusivity for minor modifications, shifting the focus of innovation promotion to the use of prizes to address specifically identified disease targets, expanding and improving the use of government (and private foundation) subsidies to channel R\&D investment more appropriately, and working to disaggregate the reward for developing innovative products from the prices consumers ultimately pay for medicine.

A critical aspect of the innovation equation involves the lack of attention to diseases primarily affecting individuals in poor and primarily tropical countries, the so-called neglected diseases. These are diseases like sleeping sickness, dengue fever and Chagas disease. Because the individuals who require treatments for these diseases are without financial resources, there is, as noted above, no market-based incentive for investing in $R \& D$ on pharmaceutical products to treat them. During the past five or six years a number of public-private partnerships have evolved to pursue research on these treatments, and so far the prognosis is fairly good. But these efforts must be sustained, and this will require continued effort and attention.

There are a significant number of obstacles to overcome when attempting to define and recommend truly global policies on innovation. The financial and human resources available to governments and private sector investors differ widely. The disease profiles of countries vary depending on a variety of factors, including climate, geography and income level. Industrial policy as regards promoting the development and/or maintenance of pharmaceutical manufacturing is an important element affecting innovation policy.

Governments are also limited in the range of innovation policies they 
may adopt as a consequence of more or less globally applicable rules adopted for countries that are members of the World Trade Organization (WTO) that is now virtually all-embracing. These rules are embodied in the Agreement on Trade-Related Aspects of Intellectual Property Rights (or TRIPS Agreement) that entered into force on 1 January 1995. The TRIPS Agreement requires all WTO member countries to provide protection for pharmaceutical products and processes (with certain exceptions remaining for 'least developed' countries). A ten-year transition period that permitted developing countries like India to avoid granting protection expired on 1 January 2005 , so that essentially all countries with advanced pharmaceutical production capacity are today required to provide patent protection.

Patents are not the only form of intellectual property protection available to pharmaceutical originators. Public health regulatory authorities in a substantial number of major jurisdictions grant a period of marketing exclusivity to the first party that obtains approval for a new pharmaceutical product. The theory behind such exclusivity is that it rewards the originator company for investing in clinical trials. In the European Union (EU), there is a ten-year (plus one) marketing exclusivity period. In the United States, there is a five-year period, subject to supplementary clinical data-based extensions. These grants of marketing exclusivity are supplementary to patent protection, and serve to inhibit the introduction of generic versions of originator products. The United States and EU have very actively promoted the adoption of marketing exclusivity grants in other countries, including developing countries. Marketing exclusivity rights strongly enhance the power of the originator pharmaceutical companies, particularly in markets where they have not secured patents, or have secured weak patents. There is presently ongoing in the United States a critical debate in Congress concerning the extent to which originator biotechnology-based pharmaceutical products (so-called 'biosimilars') will be protected against generic competition by marketing exclusivity rules. The outcome of this debate will have an important global effect because complex biotech medicines are typically exported from the major developed countries, and because the United States recently has been successful in causing other countries to emulate its rules.

The TRIPS Agreement allows flexibility in the way governments implement their patent law, and it provides a number of exception mechanisms, such as authority to grant government use and compulsory licenses that bypass the patent holder. It remains, however, arguable whether TRIPS flexibility and exceptions are sufficient to permit developing countries, in particular, sufficient leeway to protect their best interests and to develop their own innovative pharmaceutical sectors. Moreover, the United States has led the way in striking bilateral trade deals with developed and 
developing countries that limit even further the options available in innovation policy. (These matters are discussed in Chapter 2.) This is the environment in which government policy makers presently operate.

Economies of scale play an important role in innovation and in the development of successful pharmaceutical manufacturing industries. If it is not feasible to coordinate innovation policy at a global level, it may be wise to concentrate efforts at the regional level where similarities among national capacities and needs are likely to outweigh differences, and where legal frameworks established by regional economic arrangements may provide necessary institutional structures. The theme of the potential for enhanced regional coordination and collaboration is found throughout this book.

The World Health Organization (WHO) was established to promote global public health. During the past three or four years the WHO has more actively debated innovation policy and the role that the organization may play in promoting innovation. With the adoption of a Global Strategy and Plan of Action in 2008, the World Health Assembly (the senior governing body of the WHO) has taken a significant step toward proactively encouraging new models of innovation. There is reason to be cautious about the progress that can be made at the WHO because of factors that affect governance at all multilateral organizations. With 200 national governments represented and myriad stakeholder interest groups, with the pharmaceutical industry highly active as one of the nongovernmental organizations (NGOs) in consultation with the agency, it may be difficult to reach consensus decisions that will exert a meaningful effect on national governments in the near to medium term. Over the long term we may expect the WHO to take a larger role in the development and implementation of innovation policy. For the shorter term we expect that concrete action will mainly take place at the national and regional levels.

Regardless of the way the structure of innovation policy is determined, it is essential that all countries and regions have reasonable access to new technologies that are necessary to develop and produce appropriate medicines. The international legal structure and international financial mechanisms must be tailored in a way that promotes rather than inhibits dissemination of knowledge. Innovation policy must be designed to encourage invention by providing suitable reward, but not at the expense of human suffering.

\section{REGULATION OF SAFETY AND EFFICACY}

Regulation of the pharmaceutical sector is aimed primarily at ensuring that all of the products used to treat patients are safe and effective, regardless 
of whether they are originator or generic products. There is a great deal of subject matter under the tent of safety and efficacy. The process of regulation begins in earnest when an originator company seeks approval from regulatory authorities for the introduction of a new product.

Determining whether a new medicine is indeed safe and provides therapeutic benefit (that is, is efficacious) is one of the most difficult areas of pharmaceutical regulation. New products seeking regulatory approval typically must have undergone a series of clinical trials proceeding from a basic test of safety (Phase 1), to a limited test of efficacy (Phase 2), to a wider test of efficacy and safety involving a substantial pool of human subjects (Phase 3). Based on our current state of knowledge, it is perhaps surprising that it remains so difficult to predict whether a medicine that has shown some promise in test tubes (in vitro), or in animal testing (in vivo), will prove safe and effective when tested on groups of human subjects. Even when the findings in pre-marketing studies in man are positive it remains difficult to extrapolate from these in order to anticipate the effects of medicines taken over longer periods of time. Recent experience with the Cox-2 inhibitors (wherein use for an extended period proved to pose a significantly heightened risk of coronary event) illustrates this point, as well as the absolute necessity for complete openness as regards the results of clinical work.

In principle, medicines should not harm the patients whom they are intended to treat. Yet this is not an absolute standard. Most medicines have some undesirable side effects, at least in certain patients. The objective of regulation is to make sure that these side effects are appropriately proportionate to the benefits the medicines are conferring. We should not put patients at risk in treating common headaches. We may elect to tolerate more significant risk in treating late stage cancer.

In recent years there has been very substantial criticism of a common industrial and regulatory practice of maintaining the confidentiality of the results of clinical trials. This prevents independent researchers from having a close look at the data underlying the conclusions presented to regulators. As a result of this criticism - based on unfortunate real world events - there is now a modest trend toward disclosure of clinical trial results, largely on a voluntary basis in some countries. There are proposals, discussed in this book, to require making all clinical trial results public, or even to shift responsibility for the conduct of clinical trials to the public sector.

It is of some interest that clinical trials in most countries are primarily designed to compare the new medicine with a placebo, and not with existing therapies for the same condition. The regulator approves a new medicine not because it is better than the established medicines, but because it 
has some benefit in comparison to the placebo. This can naturally lead to confusion in the prescriber marketplace (i.e. doctors, pharmacists and so on), and among consumers. We are accustomed to thinking that a newer product is better than an older product - otherwise, why would we be inclined to buy the newer (and often more expensive) product? This is where pharmaceutical industry marketing exerts an unfortunate influence. Not only does it exploit to the full the instinctive belief that newer is better; it also stresses whatever evidence might be considered to point to advantages of the new product, even where the comparison has not been entirely objective or relates to a matter of no relevance to practice.

There is also a question regarding the extent to which the standards used to judge safety and efficacy should be modified to take into account the circumstances of real life. For example, in light of the extensive threat to sub-Saharan Africa presented by HIV/AIDS, should a potential breakthrough treatment be subjected to a shortened testing period because delay in introducing the product may result in numerous unnecessary deaths? Such an argument has often enough been advanced, all too easily obscuring the fact that longer term studies are not a mere bureaucratic formality; if a product is released relatively early, critical study will still need to continue in order to confirm (or refute) the earlier evidence that it possesses an acceptable degree of efficacy and safety.

As if this were not enough reason for concern, one must add that even bodies such as the US Food and Drug Administration (FDA) have now begun to experience serious doubt as to some of the evidence of efficacy and safety that they have normally been willing to accept; a very widely used cholesterol-lowering drug accepted by the agency in 2002 has still not been shown to provide any real health benefit and is now suspected of inducing malignancies. ${ }^{2}$

As the technology of medicines changes - broadly moving from synthetic organic chemistry to biotechnology - regulators are finding themselves faced with a host of new challenges, discussed in some detail in Chapter 3. The molecular structure of biotechnology-based medicines is much more complex than the structure of chemistry-based medicines. The potential for longer term effects based upon alterations of human physiology is significantly increased by the introduction of biological medicines. It is a subject of some debate whether the current mechanisms used for evaluating synthetic medicines can be adapted with only minor modification to evaluate biotechnology-based medicines, or whether a new set of regulatory assessment tools is required.

The need to ensure an acceptable level of safety also means that medicines must be produced to the standard of quality needed to ensure that the patient is receiving precisely what is intended, nothing more and 
nothing less. The production of medicines is typically undertaken in facilities in which environmental factors are carefully controlled, with inputs (that is, active pharmaceutical ingredients (APIs) and excipients) that have been rigorously tested against benchmark standards. It is the job of regulatory authorities to assure that pharmaceutical producers maintain good manufacturing practices (GMP). As will be discussed, however, there are different levels of GMP depending upon the standards of the regulator and upon the type of product being manufactured.

There are major problems in the global supply chain relating to the quality of basic materials used in the manufacture of medicines. A few regulatory authorities in OECD countries - including the US FDA and the EU's European Medicines Evaluation Agency (EMEA) - employ (or have access to the services of) substantial numbers of inspectors undertaking rigorous examinations of production facilities to assure that quality standards are maintained. The work of these inspectors extends to foreign production facilities that export products to the United States and/or the EU. Thus, an Indian API manufacturer exporting to the United States must have its facility inspected and approved by the US FDA. (Of course, experience reported in 2008 with exports of heparin from China illustrate that even this cross-border system has its weaknesses ${ }^{3}$.) However, for those products manufactured in China, India and other emerging economy countries that are not destined for the OECD markets, there is a very much weaker regulatory structure. This leads to significant quality problems not only within those countries, but also for importers in regions such as Latin America that rely upon foreign-produced APIs. There is a critical need to improve the regulatory structures in the major API exporting countries - and one must hope that this will be attained before some catastrophic public health failure ensues.

What is striking about the regulation of safety and efficacy from a global standpoint is the fact, already alluded to above, that most countries still maintain their own standards and regulatory approval processes for allowing medicines to be placed on the market. There is doubtless some value in heterogeneity among regulators in that different systems of assessment may yield somewhat different results. Yet, overall, the present system creates significant obstacles to the efficient worldwide supply of necessary medicines as producers are required to pass through regulatory hurdles in each separate jurisdiction. This limits the availability of medicines, and may well increase prices. There is perhaps no better candidate for regional regulation than the field of medicines.

Countries sharing more or less common geography, more or less common disease burdens, and more or less comparable levels of income should be able to cooperate in regulating the introduction of medicines onto their 
collective markets. By reducing the need for multiple regulators when medicines are introduced, governments could refocus the attention of regulators towards assuring the quality of those medicines that are currently on the market, paying more attention to the quality of medicines at the point-of-sale. A regional approach to the inspection of production facilities - including the dispatch of adequate teams of inspectors to countries of origin - may be effective in terms both of cost and of public health.

The WHO has, despite the fact that it has no regulatory powers of its own, played an increasingly significant advisory role in establishing regulatory standards in the area of GMP compliance. It has now undertaken an important program to pre-qualify manufacturers supplying HIV/ AIDS antiretroviral treatments and certain other HIV-related products. By doing so, the WHO is demonstrating its potential capacity as an institution possessing considerable technical abilities, while at the same time highlighting the weaknesses of regulatory capacity in major API producing countries, like India.

Rules governing the safety and efficacy of medicines are only effective if they are enforced. Regrettably, there have been a significant number of notable regulatory failures that have permitted the introduction of dangerous products onto the market. Sometimes this has happened because of oversight by regulators, but it has also happened because of deliberate or negligent failure on the part of the pharmaceutical industry. It is therefore fortunate that private citizens have in such situations been able to play an important corrective role by seeking redress in the courts, thus ensuring that regulators and the industry pay attention to the legal and ethical rules that govern these matters. The courts, for their part, have played an important role by listening to private citizens and, in a good number of cases, providing relief. Unfortunately there are some worrying trends in the United States toward cutting back on the access of private citizens to redress. In 2008 the US Supreme Court had under submission a case in which the industry sought a safe harbor for pharmaceutical products that have been approved by the US FDA. Wisely, in March 2009 the Supreme Court decided against providing such a safe harbor.

\section{REGULATION OF PRICING AND AVAILABILITY, PROMOTION AND EDUCATION}

The maintenance of patents and other forms of marketing exclusivity, discussed above, is surely the single most important factor in permitting the originator industry to charge high prices for newer medicines. Nonetheless, governments are not without regulatory mechanisms to control pricing 
and availability. It is not uncommon for governments to impose price controls on pharmaceutical products. These controls may be based on different factors or benchmarks, including reference to prices in other countries or cost-plus formulas. Direct price controls are not the only method for controlling the price of medicines. Many countries have adopted generic substitution laws that require pharmacists to provide the customer with a low-cost generic version of a patented medicine when that is available.

Pharmaceutical consumers are often not aware of the real price being paid for their medicine. Some public health systems provide medicines free of charge or at purely nominal cost. Many consumers, such as in the United States, receive medicines under a prescription benefit plan that requires the patient to make some co-payment that is small as compared with the actual price paid for the medicine by the health insurance provider. This makes consumers less price-sensitive than they might be if they were paying the actual price of the medicine. There is therefore no strong public lobby to insist on reasonable levels of medicine pricing, such as there would be if the extent of overcharging were more widely known.

Demand for medicines is heavily influenced by advertising and promotion. Such promotion is permitted in most countries with respect to physicians. A very few countries permit direct to consumer (DTC) advertising. The originator industry argues that DTC advertising provides consumers with information they would not otherwise have, and may encourage them to seek advice and treatment from qualified physicians. Critics of DTC argue that it stimulates over-prescribing and over-consumption of medicines. If an individual really needs treatment, he or she is surely likely to find the way independently to a doctor who will provide it, without pushing from the pharmaceutical industry.

One of the most difficult aspects of pharmaceutical policy is the task of encouraging physicians (and other prescribers) to understand the complex effects of the medicines they are recommending to patients, as well as educating patients regarding best practices in the use of medicines. The Internet has been a game changer in this regard, making vast amounts of information about medical conditions and treatments generally available, information that varies considerably as regards its balance and reliability. At the same time, the Internet is a largely unregulated environment that may encourage consumers to pursue courses of treatment that are not in their best interest.

\section{ACCESS AND AFFORDABILITY}

Without innovation, new medicines will not become available. But new medicines that are not affordable present a major global problem. This is 
not a problem confined to poor countries in Africa, or to developing countries in Latin America and Asia. The United States is facing a looming budgetary crisis as health care costs for an aging population weigh on the federal budget. The uninsured and underinsured face enormous difficulties paying for needed pharmaceutical treatments. Even in Western Europe, with its extensive provisions for the social coverage of health costs, the pressure on available budgets has reached the point where expenditure may have to be cut back unless unit prices can be reduced. A recent paper from Britain's National Institute for Health and Clinical Excellence (NICE) on a series of drugs for the treatment of renal cancer concluded that for one of them the cost of providing an extra year of life was no less than $£ 171,300$ (approximately $\$ 297,000$ ). ${ }^{4}$ Even a relatively wealthy nation, before considering whether it can accept such expense, has the right to enquire whether or not it is justified by the sums required for research and production.

While there is general agreement that the cost of researching and developing new medicines is high, the necessary level of investment in R\&D is much debated. However the figures are calculated, there is a tremendous difference between the amounts spent globally on $\mathrm{R} \& \mathrm{D}$ and the aggregate amounts paid for new pharmaceutical products.

The major originator pharmaceutical companies claim to spend an aggregate of about $\$ 55-60$ billion per year worldwide on R\&D. ${ }^{5}$ The US federal government, mainly through the National Institutes of Health, spends about US $\$ 30$ billion per year on pharmaceutical-related R\&D (predominantly funding basic research), and in various other countries there is also a degree of public funding. Total global R\&D on new pharmaceutical products in a given year is claimed to be about $\$ 100$ billion (giving a generous allowance to the industry estimates).

The cost of producing originator pharmaceuticals represents a significant part of their selling price. Using figures reported by the originator industry, annual total production costs in 2007 can be roughly approximated at about $\$ 137.5$ billion. $^{6}$ The production costs for the originator companies, particularly those manufacturing in the major developed countries, reflect significant investments in compliance with rigorous regulatory standards. One of the major challenges for the global regulatory system is to assure that some countries do not achieve competitive advantage based on inappropriately reduced regulatory compliance levels or costs. At the same time, originator production processes in the major developed countries might well be made more efficient. There is reason to ask whether the price shield these companies have enjoyed based on patents and marketing exclusivity protection has not unduly reduced their incentives to improve production efficiencies. We are not suggesting or 
advocating that any country outsource its pharmaceutical production to save compliance and/or labor costs. We do, however, suggest that a closer look might be taken at ways to improve production efficiencies based on the successes of the major generic suppliers like Israel-based Teva.

If it is correct that $\mathrm{R} \& \mathrm{D}$ in total is costing $\$ 100$ billion yearly, while production costs add some $\$ 137.5$ billion, the remaining $\$ 312.5$ billion in the price paid for originator products is going to something else. Where is it going?

There are basic supply chain costs (transport, storage, physical distribution and so on). A major element represents amounts expended on marketing and promotion. These marketing and promotion costs, as discussed in Chapter 6, sometimes represent reasonable expenses connected with educating physician and pharmacy professionals as to the profile and proper usage of new medicines. Often and increasingly these expenditures are bypassing medical professionals and going directly to the consumer, with very questionable intent and effect.

There is administrative overhead and employee salaries - including sometimes astonishing sums paid to senior pharmaceutical industry officers. There are dividends paid to investors.

At the end of the day, consumers around the world (including government public health ministries and hospitals) are spending $\$ 550$ billion for $\$ 100$ billion in R\&D, $\$ 137.5$ billion in production costs and $\$ 312$ billion for a very expensive something else. It is hard to escape the conclusion that there is a better way to deliver value to the global consuming public. Somewhere within the $\$ 550$ billion paid to the originator industry there must be financial room to provide powerful incentives for innovation, and the production and distribution of high-quality medicines, while at the same time providing affordable medicine to people around the world.

\section{CONCLUSION}

In this book we examine a range of policies and institutions involved in promoting innovation, developing and implementing regulations, and trying to assure affordable access to high-quality safe and effective medicines. It is difficult to synthesize a set of recommendations in a few short sentences. But we would like to highlight a few that strike us as critical.

First, the system for promoting innovation worldwide must be refocused on the development of new therapeutic classes, with the lesser emphasis on extending product lines through minor modifications. There are various ways to address this objective by retooling the patent system (including to introduce quasi-patents to protect minor modifications), by extending and improving subsidy programs, by the use of targeted prizes and others. 
Second, additional transparency must be introduced into the system by which medicines are assessed and approved.

Third, the marketing of prescription pharmaceutical products directly to consumers introduces both direct costs of promotion, and indirect costs from elevated demand. The heavy promotion of new prescription products increases risks that unforeseen injurious effects will be spread more widely. There is good reason to curtail the trend towards DTC advertising of these products.

Fourth, private civil litigants play an important role in increasing transparency and identifying pharmaceutical product risks, in addition to redressing injury. Courts should be very wary of curtailing the role of private litigation (for example, US state causes of action should not be pre-empted by federal law). If the US Supreme Court moves in this direction, Congress should step in to correct the situation. ${ }^{7}$

Fifth, there is a great deal of regulatory cost imposed by country-tocountry assessment of pharmaceutical products. While some degree of regulatory heterogeneity is necessary and appropriate to take into account matters such as differences in climate and disease patterns, it is not necessary that every country review and approve every drug. In light of the current state of global political affairs, we recommend increased efforts on a regional basis to cooperate on and coordinate medicines regulatory policy and implementation.

Sixth, it is important that low-income developing countries maintain focus on essential drugs policies that seek to assure wide access to the most needed treatments. This is particularly important as the 2009 global economic climate threatens to reduce even modest levels of support from developed countries. It remains vitally important that developed countries continue to provide support for medicines purchases for countries and populations that are not viable participants in the global pharmaceuticals market.

\section{NOTES}

1. The vast part of the world economy is not 'coordinated' by any central authority. The system for development and supply of pharmaceutical products is not so different from that of other types of goods and services. For automobiles, banking, energy, food and entertainment products, decisions are taken primarily by companies operating in the private sector with some degree of control by national government authorities and a lesser degree of oversight or regulation by multilateral institutions.

2. Dr Robert Temple (FDA), as cited by A. Berenson, 'A popular drug with uncertain benefits', Int Herald Tribune, 2 September 2008.

3. See, for example, Walt Bogdanich, 'Heparin is Now Suspected in 62 Fatalities Across U.S.', Times, 10 April 2008. 
4. Anon., 'NICE turns nasty: what lies behind a tiff over drug pricing', The Economist, 21 August 2008.

5. According to the website of the Pharmaceutical Research and Manufacturers of America (PhRMA), 'PhRMA members alone invested an estimated \$44.5 billion in 2007 in discovering and developing new medicines. Industry-wide research and investment reached a record \$58.8 billion in 2007', http://www.phrma.org/about_phrma/ (accessed 26 October 2008).

6. Based on the 2007 annual Form 10K filings with the US Securities and Exchange Commission of Pfizer and Merck, and the Form 20-F filing of Novartis, originator companies claim costs of goods/materials and production of about 25 percent of gross revenues (Pfizer claiming costs of $\$ 11.239$ billion on revenues of 48.418 (or 23.2 percent), Novartis claiming costs of $\$ 11.032$ billion on revenues of 38.947 (or 28.3 percent), and Merck claiming costs of $\$ 6140$ billion on revenues of 24.197 (or 25.4 percent)).

7. In March 2009, the Supreme Court of the United States rendered its decision in Wyeth v. Levine, No. 06-1249, decided 4 March 2009 (slip opinion available at http://www. supremecourtus.gov/). The court held that the labeling provisions of the federal Food, Drug and Cosmetic Act do not preempt state law causes of action for mislabeling of pharmaceuticals. 